\title{
The Third European Trainees Forum
}

\author{
Laurence Sheldon and Peter L. Cornwall
}

The Third European Trainees Forum met in Copenhagen in May 1995. Twenty-nine delegates from fourteen countries came together to discuss training issues in the European context. Newcomers representing France, Spain and Italy joined representatives from the United Kingdom. Ireland, Norway, Denmark, Sweden, Finland, Greece, Switzerland, Germany, The Netherlands, Belgium, and Portugal. As in previous years, the Forum addressed a number of specific training topics and discussed furthering links with other European psychiatric bodies.

One of the aims of the Forum is to encourage trainees in member countries to form national trainee organisations. Two years ago only four countries had done so-UK. The Netherlands, Ireland and Denmark. The position has improved with the encouragement of the Forum and new national trainee organisations have sprung up in Sweden, Finland and Italy. Barriers to establishing these often exist such as funding difficulties or structural obstacles such as in Belgium where there is a complete separation of Flemish and French-speaking psychiatric trainees.

The further expansion of the Forum was discussed: contacts are being made with Austria and Iceland. Luxembourg, we were informed, has no psychiatric trainees: their psychiatrists train in Belgium. Some talk centred on the Eastern European countries, the Baltic States and Russia, but the general view was that it was still too early for the Forum to go beyond the confines of its current Western European membership.

The Forum has established links with several other European psychiatric bodies. Representatives of the Forum now attend meetings of the European Board for (Adult) Psychiatry and the European Board for Child and Adolescent Psychiatry as observers. A Forum representative joined a World Health Organization consultation team travelling to Romania this Summer to comment on their newly-established five-year psychiatric training programme.

Many trainees are attracted to the possibility of undertaking a portion of their training in another European country. When this does occur, it is on an ad hoc basis, dependent on the goodwill of their clinical tutor or hospital director. Financial considerations are often a strong deterrent in the less affluent European countries. At the meeting no European body could be identified that would fund or organise such exchanges.

The Forum discussed the proposed minimum requirements for specialist training put forward by the European Board. The UK and Ireland still have the longest training. Three other countries (Italy. France and Spain) had training for four years and the rest five years. Our personal view is that training in the UK is among the best in Europe, particularly when hearing of the deficiencies or vagarles of training in other European countries. Indeed, several delegates commented on the reputation of the Royal College in maintaining the standards of training in the UK and Ireland. Great interest was also shown in the recent College publication Psychiatry in Europe (1994).

This year the Forum will be hosted by Portugal which will also assume the presidency for the year. Topics on the agenda are likely to include logbooks, guidelines on how to create national trainees' organisations, acquisition of teaching and supervision skills, and the selection of psychiatric trainees. English continues to be the lingua franca of the Forum. Until now funding for the Forum has been generously provided by the Dutch Psychiatric Association. It was agreed that funding would in the future be obtained from the respective National Trainees Organisation (if it existed) as well as from delegates' fees. The Forum continues to establish itself as an independent representative body for all psychiatric trainees with the aim of influencing training throughout Europe.

\section{Reference \\ Sensky, T., KATONA, C. \& MONTGOMERY, S. (1994) Psychiatry in Europe. Directions and Developments. London: Gaskell.}

Laurence Sheldon and Peter L. Cornwall, Collegiate Trainees Committee

Correspondence: Dr L. Sheldon, Senior Registrar, Child \& Adolescent Psychiatry. St George's Hospital Medical School, Jenner Wing, Tooting, London SW17 ORE 